\title{
Presentation of Existing Architectural Objects Using Augmented Reality: Case study - Ada Bridge, Belgrade, Serbia
}

\author{
Petar Pejić ${ }^{1}$, Taško Rizov ${ }^{2}$, Sonja Krasić ${ }^{1}$, Risto Taševski ${ }^{2}$ \\ ${ }^{1}$ Faculty of Civil Engineering and Architecture, University of Niš, Niš, Serbia; ${ }^{2}$ Faculty of Mechanical Engineering, Ss Cyril \\ and Methodius University of Skopje, Skopje, Republic of Macedonia
}

\author{
Citation: Pejić $P$, Rizov $T$, Krasić $S$, Taševski R. Presentation \\ of Existing Architectural Objects Using Augmented Reality: \\ 2015 Dec 30; 2015:10011. http://dx.doi.or \\ 10.3889/seejad.2015.10011 \\ Key words: presentation of existing architectural objects; \\ augmented reality; $3 \mathrm{D}$ model; android application. \\ Correspondence: Tašo Rizov. Faculty of Mechanica \\ Engineering, Ss Cyril and Methodius University of Skopje, \\ tashko.rizov@gmail.com \\ Received: 06-Nov-2015; Revised: 26-Dec-2015; Accepted: \\ Received: 06-Nov-2015; Revised: $26-$ -
27-Dec-2015; Published: $30-$ Dec-2015 \\ Copyright: ๑ 2015 Petar Pejić, Taško Rizov, Sonja Krasić, \\ Risto Taševski. This is an open-access article distributed \\ which permits unrestricted use, distribution, and reproduction \\ in any medium, provided the original author and source are \\ credited. \\ Competing Interests: The author have declared that no \\ competing interests exist.
}

\begin{abstract}
The presentation of existing architectural objects is most often done because of its historic significance or design values. Contemporary methods of presentation imply the use of digital perspective images, videos virtual reality or augmented reality. Augmented reality (AR) is computer technology where the perception of the user is enhanced by the seamless blending between real environment and computer-generated virtual objects coexisting in the same space. In this paper a case study of AR use for existing architectural object presentation for "Ada Bridge" across Sava River in Belgrade is presented.
\end{abstract}

\section{Introduction}

Augmented reality (AR) is an emerging computer technology where the perception of the user is enhanced by the seamless blending between a realistic environment and computer-generated virtual objects coexisting in the same space [1]. The resulting mixture supplements reality, rather than replacing it [2].

According to Azuma [3], Augmented Reality (AR) is a variation of Virtual Environments (VE), or Virtual Reality as it is more commonly called. In these so called Virtual Environments the user is completely surrounded by a synthetic environment. In that state, the user can not perceive the real world and the real environment that surrounds him/her. On the contrary, the Augmented Reality (AR) allows the user to perceive the real world while the virtual elements are superimposed upon or composited with the real world [4]. In this manner, the augmented reality is enriching user's perception of the reality rather than totally replacing it like in the case of the virtual environments. The ultimate goal of the AR is to convince the user that the two environments, real and virtual, coexist. According to Azuma augmented reality presents a system with the following characteristics: (1) combines real and virtual world, (2) interactive in real time and (3) registered in $3 D$ [3]. In that regard, the AR improves our perception of the reality and the real world that is around us, and in the same time it enhances the way we interact with it. The idea behind the technology is to present the user with the ability to perceive information that using the normal natural senses are not directly detectable. Still, the enhancement of the user's reality should help the user in completing regular real-world tasks and activities.

The technology of Augmented Reality can be used to augment all of the user senses, although the vast majority of applications are focused only to the sight by combining virtual graphics with the reality the users sees. There are available researches and appli- 
cation of haptic devices that augment the tactile sense of the user, while the augmentation of sound and smell are still limited.

When creating an AR system the basic dilemma is how to achieve the needed mix of reality and virtual objects. Basically, two options are available: optical and video technologies. Each has particular advantages and disadvantages [5]. By using standard Head-Up Displays (HUD) an augmentation of the vision is easily achieved. A simple HUD can be achieved by using a hand-held device and its camera and display.

The presentation of a particular architectural facility is most often done because of its significance and attractiveness. The following things are promoted through the presentation of a particular facility:

- cultural and historical significance and the tradition of a city or a region where it is located; or

- contemporary architectural design values of its location.

Traditional methods of presentation imply 2D photos of the facility or 3D animations and video clips. Technology development has enabled web 3D view of the models of facilities even for users with basic computer literacy. Still, these methods do not present the virtual object in its natural surroundings, thus making the presentation of the project incomplete. With the application of augmented reality, the computer generated three-dimensional models of existing or new architectural facilities are presented in an intuitive way and in their environment closing the loop of the presentation process where the user besides the "look" of the object can also "see" how the object blends in its surrounding [1].

In this paper a case study of AR use for existing architectural object presentation for "Ada Bridge" across Sava River in Belgrade is presented. For this purpose authors develop an Android based augmented reality application "Ada Bridge AR" [6]. Application is tested and working results are presented in this paper.

\section{Materials and Methods}

This paper presents the process of creating an Augmented Reality application for 3D interaction in reality with a virtual model of a new architectural structure. As an architectural structure the Ada Bridge in Belgrade was selected. The solution for the new Ada Bridge (Figure 1) over the River Sava in Belgrade is a comprehensive synthesis of urban planning, construction and architectural design. Following the design of the bridge, it spans the Sava 'in a leap' by means of two wide arches abutting on the river banks and on Ada Ciganlija, the island in the middle.

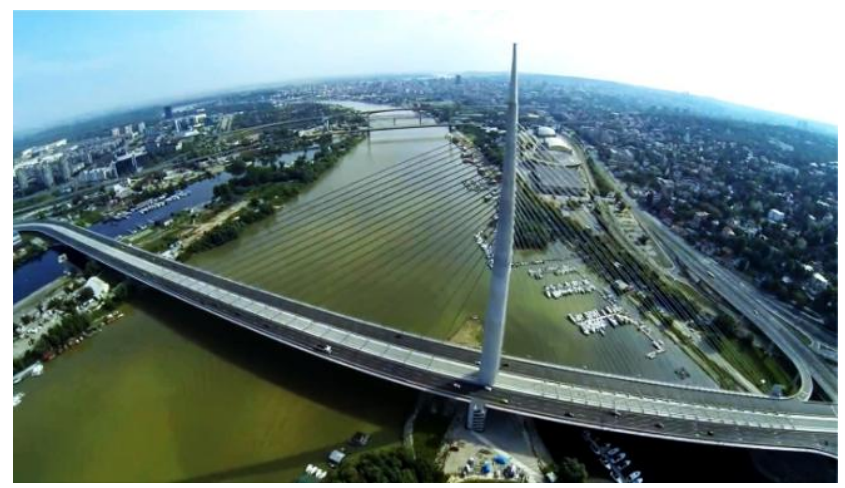

Figure 1: Ada Bridge

At the very promontory of the island Ada $\mathrm{Ci}$ ganlija a $207 \mathrm{~m}$ high pylon was erected to enable two asymmetrical spans to cross the river by means of 80 steel backstay cables. The new bridge is $920 \mathrm{~m}$ long, with a span of 375 meters. The carriageway is 45 metres wide, with six lanes for road vehicles, two light rail railway tracks, and two pedestrian and cycling paths. This is the largest bridge surface in the world suspended by just one pylon. The bridge incorporates numerous superior characteristics and successfully meets many technical challenges.

The shape of the pylon results from a functional and constructional idea of the appearance of the bridge. The bridge is divided into three carriageways. The pylon transfixes the carriageway construction in such a way as to maintain its appearance and become the element linking the separate parts of the bridge into an integrated composition. It rises in the form of a slim, pointed cone anchoring the backstays. The bridge construction and its design as well as the construction of the pylon stem from both engineering and architectural aesthetics. The accent is on the pylon's peak, which completes the ideal geometrical line of a slim cone, thus conferring on the bridge an accentuated symbolic power and identity.

The pylon's superstructure was implemented in the form of a light metal structure which when illuminated is a significant landmark in the city's night life. Speaking of the perception of space, the pylon may be experienced in multiple ways: as an element of the environment, indicating the position of the river island, as a part of the new urban architecture, or as a part of the bridge architecture in a stricter, ambient sense. In conceptual terms, it may be ranked among similar symbolic elements by which, in the course of history, we would mark significant spots or events in space: now, we can view it as an urban sculpture or a new city 'cathedral', which physically and symbolically connects the new and the old Belgrade [7].

After an analysis of the possibilities to aug- 
ment the reality with a virtual object of the selected architectural structure, the option for using a 3D model of the bridge and an aerial video of the same architectural structure was selected. The idea behind this solution was to provide the users with the ability to see the 3D model of the Ada Bridge presented on the real view of the standard map of Belgrade. This idea was selected since the standard map of Belgrade is easily available at hotels and touristic info points around the city.

After an analysis of the possible methods for achieving the augmentation was conducted. This analysis evaluated the advantages and disadvantages of various methods for achieving the desired augmentation. The results of the analysis are presented in Table 1. The analysis values the different advantages and disadvantages of both display methods and available software AR builders. The evaluation takes into consideration the ability to build AR scenes for different display devices, the ease of the programming process as well as the quality of the achieved augmentation.

Table 1: Analysis of methods for augmentation

\begin{tabular}{lcccc}
\hline Device & $\begin{array}{c}\text { Head-Mounted } \\
\text { Display }\end{array}$ & $\begin{array}{c}\text { Head-Up Dis- } \\
\text { play }\end{array}$ & Projection & Total \\
Software & 0 & 3 & 5 & 8 \\
\hline BuildAR & 5 & 5 & 5 & 15 \\
Unity & 0 & 5 & 0 & 5 \\
Layar & 2 & 4 & 0 & 6 \\
Augment & 2 & 5 & 0 & 7 \\
Junaio & 9 & 22 & 10 & \\
TOTAL & & & &
\end{tabular}

The conducted analysis shows that the use of the use of Head-Up Display and the software application Unity are most suitable for this application. That result is because of the fact that the HUDs are widely available and with lower cost for use. The AR builder software Unity provides most options and high quality of augmentation.

In order to create Augmented Reality presentation of Ada bridge, a 3D bridge model available from "3D Warehouse" was used [8], and an aerial video of the bridge from "Youtube" [9]. For development of the Android application, the development engine "Unity" was used [10].

\section{Augmented Reality Application}

Using Unity development engine (Figure 2), 3D model of Ada Bridge is connected with marker (Figure 3). As a marker a picture which present geographic map of Belgrade with location of Ada Bridge is used. Second marker (Figure 1) is connected with areal video of Ada Bridge.

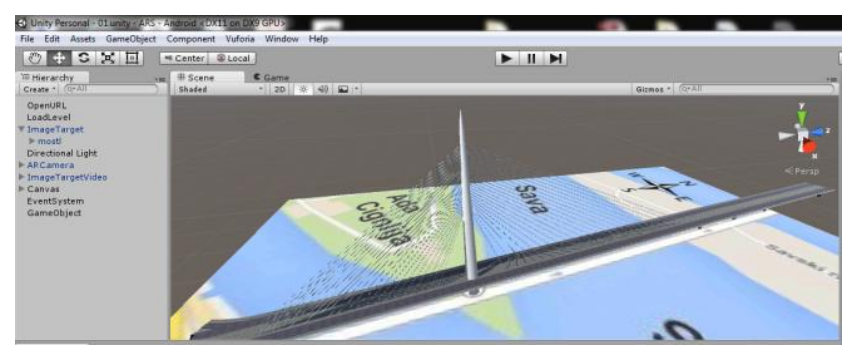

Figure 2: Creation of application in Unity

These markers are connected to "AR camera" in order of Augmented Reality presentation. We create second page with information about authors and link with additional web information (Figure 4). Created android application "Ada Bridge AR" is available for download on official Google Play app store [6].

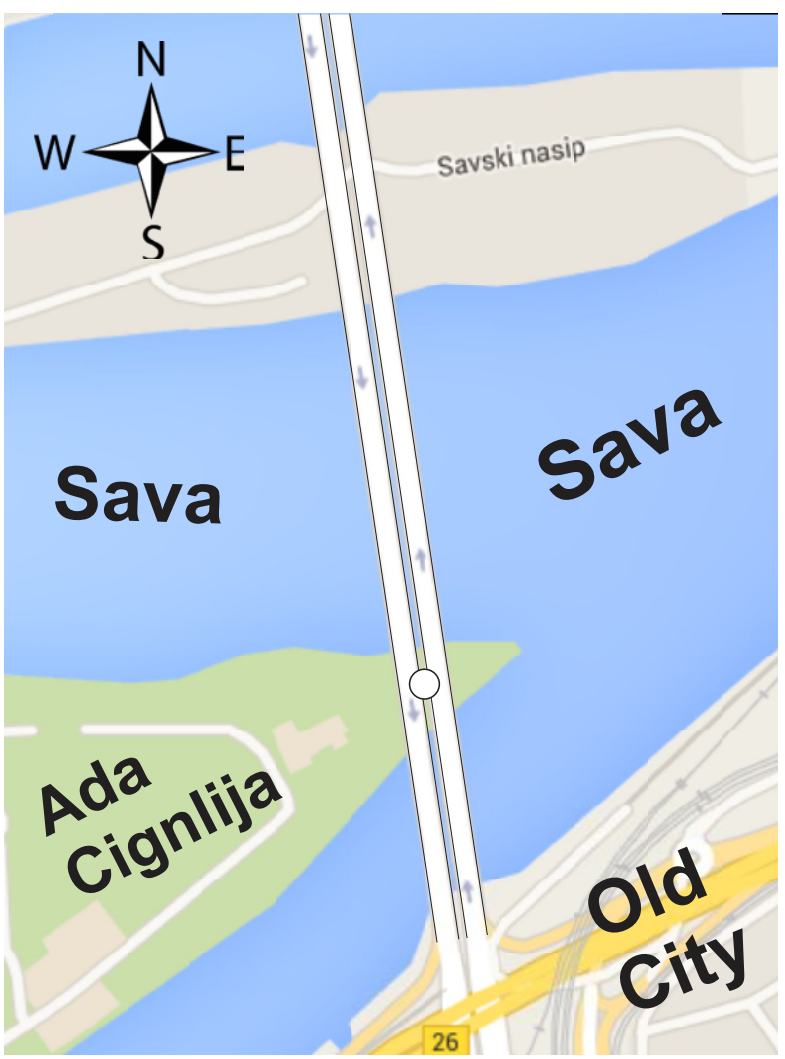

Figure 3: Marker for 3D model presentation

Created android application is tested using "Project Tango" tablet and appropriated markers. After starting the application, the device camera records real surrounding, while the application is searching for predefined markers. When the application detects the location of the marker (Figure 3), on the display of the device we can see a3D model of the Ada Bridge connected with marker. Moving the marker will cause joint move of both the marker and the 3D model of the bridge on the device display. If the device camera detects other markers (Figure 1), on the display of device we can see video which is connected with the marker (Figure 6). 


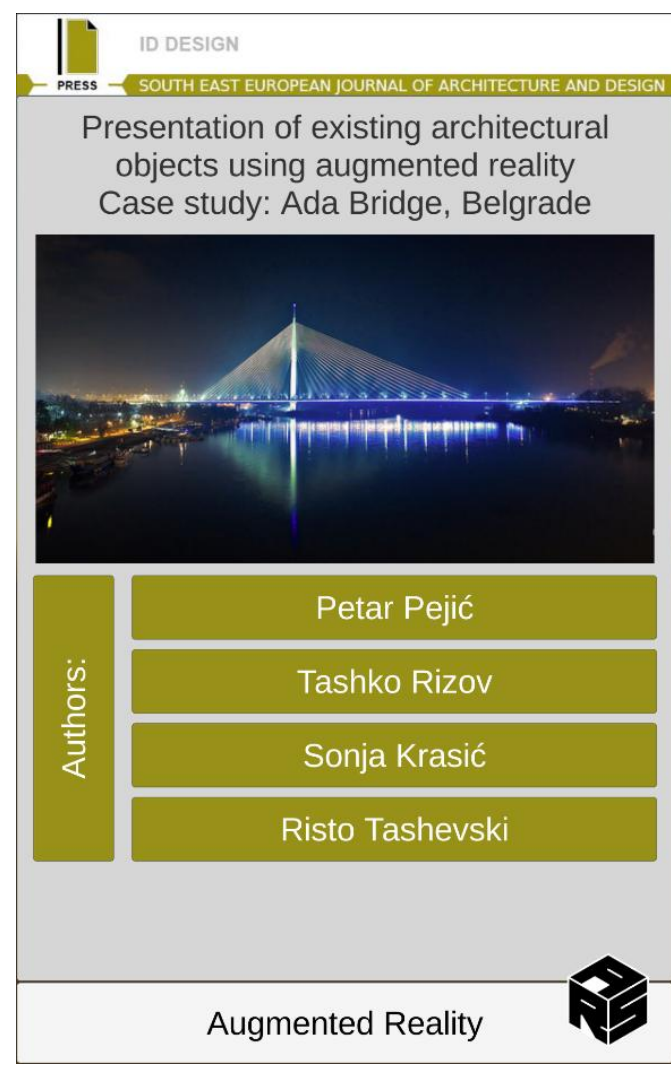

Figure 4: Informational page in application

This approach changes static two dimensional pictures in video, using smart device and Augmented Reality technology.

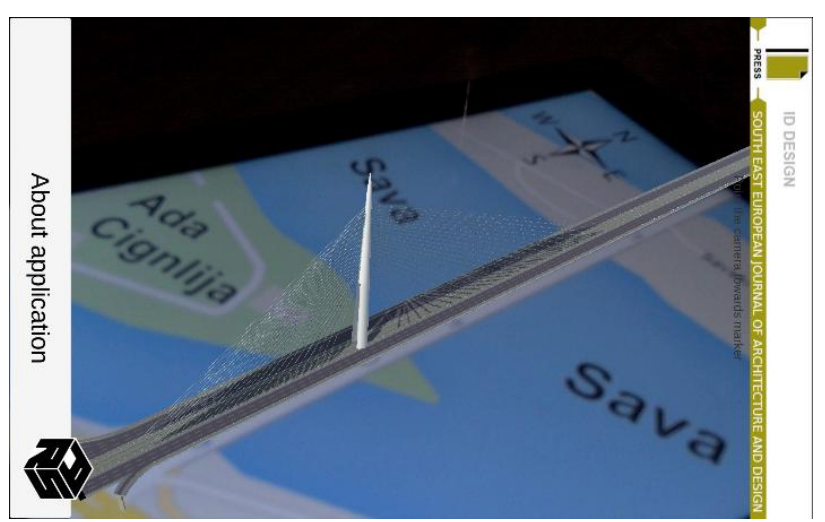

Figure 5: AR presentation of 3D model

In conclusion, this paper is aimed to demonstrate contemporary method for presentation of the existing architectural objects. Application of the AR in existing architectural structures presentation is a cutting-edge tool. This approach enables the spatial presentation of the 3D model within the real environment. It allows the user to view the existing architectural structures as small scale models inside the real surrounding. By using commercial mobile devices and free Android software the preview can be seen.

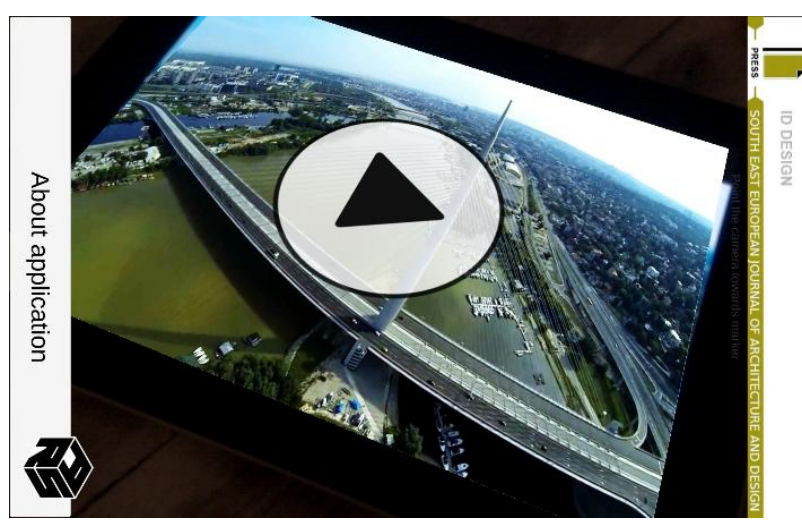

Figure 6: AR presentation of video

The use of the application itself is completely intuitive. The quality of the 3D model presentation is at a good level, but it is much worse than the areal video footage. It is caused by the limited processing capabilities of the devices and complex calculations needed for the proper functioning. Augmented reality presentation of $3 \mathrm{D}$ model presents great tool for presentation of architectural object. It does provide better understanding of architectural structures because the user can choose which part of the structure and from which point of view of the architectural structure he/she wants to see.

\section{References}

1. Pejić P, Krasić, S, Jovanović N. The application of augmented reality in the presentation of existing architectural facilities. International conference MoNGeometrija 2014, Vlasina, Serbia, 1, 74-81.

2. Pejić P, Krasić S, Petković D, Veljković M. Application of augmented reality in facade redesign presentation. Journal of Industrial Design and Engineering Grapphics. 2015;10(4):45-49.

3. Azuma R. A Survey of Augmented Reality, Teleoperators and Virtual Environment, 1997:355-385.

4. Sutherland IE. A Head-Mounted Three-Dimensional Display. Harvard University, 1968.

http://dx.doi.org/10.1145/1476589.1476686

5. Wagner D, Barakonyi I. Augmented Reality Kanji Learning. Japan: ISMAR, 2003.

6. Pejić P. (28.10.2015). Google Play - Ada Bridge AR. Prevzeto 28.. 10. 2015. Accessed

https://play.google.com/store/apps/details?id=com.PetarPejic.AdaB ridge

7. Arhitektura. 2011. Archdaily. Accesses 28.10.2015. http://www.archdaily.com/212085/the-ada-bridge-arhitektura-d-o-o

8. Mihailo. (22.3.2014). 3D warehouse. Accessed 26.10.2015. https://3dwarehouse.sketchup.com/model.html?id=792473773440a bb7dd9a8bd82517cd9a

9. Dolas N. (1.9.2014.). Youtube. Accesses 27.10. 2015. https://www.youtube.com/watch?v=vF5eslcxFzM

10. Unity. 2015. Unity. Accessed 28.10.2015. https://unity3d.com/ 